

PRIMARY RESEARCH

\title{
Creative teaching as perceived by English language teachers in private universities
}

\author{
Marites Piguing Hilao *
}

Language Institute, Bangkok University, Bangkok, Thailand

\author{
Key Words \\ Creative teaching \\ Creativity \\ Language teaching \\ Perception
}

Received: 12 June 2016

Accepted: 10 September 2016

Published: 27 October 2016

\begin{abstract}
The study aimed to investigate the concept of creative teaching as perceived by university teachers and find out some factors that impacted their perceptions comprising gender, academic title, and degree. Data were collected from 164 English language teachers from five different private universities in Thailand using a 5-point rating scale questionnaire and analyzed through t-tests and One-Way Analysis of Variance. The findings reveal that teachers' creative teaching perceptions based on the six categories, namely, school environment, personal quality, personal motivation, teaching belief, education and career experience, and thinking style, were high. Regarding background information, the factor of academic title was found to have an impact on perceptions. Teachers with the academic title had higher perceptions of creative teaching than those without the academic title in all categories, and significant differences were found in overall perceptions and two categories: personal motivation and thinking style $(\mathrm{p}<.05)$. However, the other factors comprising gender and degree did not affect their perceptions. The findings can be useful for administrators in all private universities when creativity and creative teaching were implemented in the curriculum.
\end{abstract}

(C)2016 The Author(s). Published by TAF Publishing.

\section{INTRODUCTION}

To provide a better education for students' growth and development, the role of teachers is essential in the pursuance of this noble task. Teachers are encouraged to increase their level of achievements, commitment, devotion, competency and most especially their creativity. The latter was stressed by authors like Rhodes (1961) and Torrance (1963), pointing out the importance and urgency for teachers to be creative. It is believed that students' creative abilities are most likely to be developed in an atmosphere in which the teacher's creative abilities are engaged properly. School and in particular, the classroom, has been seen as a privileged context for promoting creativity in order to enhance social and individual progress (Cropley, 2009; Runco, 2004). Blagg (1999) added that in an educational setting creativity is designed to bring new, different and unexpected responses to a situation and enhances fluency, flexibility and originality in students. With this line of thinking, teachers in higher education institutions should move from chalk and talk method of teaching to a more creative and innovative style of teaching, which could motivate students to work together developing their social and interpersonal skills.

\footnotetext{
${ }^{*}$ Corresponding author: Marites Piguing Hilao

†Email: marites.h@bu.ac.th
} 


\section{Creative Teaching}

Various educators and theorists have different notions of what creative teaching is. Mayer (1989) proposed that creative teaching refers to instructional techniques that are intended to help the students learn new material in ways that will enable them to transfer what they learned to new problems; Osborn (1992) defined it as the type of teaching which causes students to think as they learn; Slabbert (1994), referred to it as to be sensitive to the individual's conception of himself and his role in the classroom. For authors like Torrance (1962; 1968), Torrence and Myers (1976), Cropley (1992) and Walberg (1991), creative teaching appears connected to certain traits, characteristics, behaviors and, especially, to techniques, methods and classroom arrangements, whose variety and complexity tend to make them lose their heuristic as theoretical construct. It is nonetheless mostly defined or focused on teaching creativity, i.e. creative thinking with the aim of enhancing creative thinking skills among students. Starko (2000) referred to it as teaching implemented for the purpose of cultivating students' creativity. It can also be described as teachers, using imaginative approaches to make learning more interesting, engaging, exciting and effective ((Morris, 2006). Thesaurus defined the concept of creative teaching as teaching that results from the teacher's creativity, not teaching intended to develop learner's creativity. Mayer (1989) added that creative teaching refers to instructional techniques that are intended to help students learn new material in ways that will enable them to transfer what they learned to new problems.

The concept of creative teaching has been incorporated in the Thai curriculum for quite some time. Especially, in language instruction, a lot of changes in the course activities were made to support more creative teaching. According to Runco and Diane (2002) it is important to know people's perceptions concerning creativity. It can be inferred that perceptions guide what we are and what we do (Romo and Vicente, 2003) and are of utmost importance for students (Rosenthal, 1991). Therefore, knowing teachers' perceptions about creativity can help to understand needs, misconceptions or even prejudice ideas, and to discern positive beliefs that should be reinforced; evaluating teachers' conceptions of creativity can help consequently to establish better practices to foster creativity in classroom (Fryer, 1996; Newton and Newton, 2009). In order to gain more understanding of what they perceive, the factors related to background information are concerned in this study.

\section{PREVIOUS RESEARCH STUDIES}

For the enhancement of creative teaching and for it to really take place, it is crucial that all significant factors affecting creative teaching are taken into account when designing the creative teaching and learning process as Palaniappan (2009) mentioned in her paper presented at the 12th UNESCO-APEID International Conference held at Bangkok that school environment, teachers' motivation, and pedagogical experiences, etc, are factors affecting creative teaching. In the study conducted by Hong, et al. (2012), however, it reveals that personal quality, family factor, growth and education experience, teaching belief, personal effort, and motivation are factors that are responsible for teachers' creative teaching behavior.

In the study exploring the factors that influence creative teaching by Horng et al. (2005), it was found that personality traits, family factors, experiences of growth and education, beliefs in teaching, hard work, motivation and administrative side of school organization are the influential factors to creative teaching in Integrative Activities.

tab Hong, et al. (2012) conducted a study on creative teaching factors and referred to it as teachers utilizing their own creativity to design systematic teaching solutions, adopting 
appropriate teaching techniques, and changing teaching methods or arranging reasonable and effective teaching activities while teaching. Thus, it would just be fair to say that teaching for creativity must involve creative teaching which means that teachers are involved in making learning more interesting and effective and using innovative approaches in the classroom. Furthermore, teaching with creativity and teaching for creativity include all the characteristics of good teaching- including high motivation, high expectations, the ability to communicate and listen and the ability to interest, engage and inspire.

Amabile (1989), on the other hand, revealed that cognitive, affective, personal and motivational, and social or environmental are the elements of creativity which she mentioned; are interconnected; each is caused by and causes the others. In other words, it has a cause and effect relationship. Urban (1995) classified creativity into three components: the cognitive aspect, personality and the environmental condition. The cognitive aspect includes divergent thinking, general knowledge, and domain-specific knowledge and skills. Personality includes task commitment, motivation and openness and tolerance for ambiguity. Environmental condition, on the other hand, includes individual, local, and global dimensions.

Combining the components of creativity and studies mentioned above, factors like school environment, personal quality/characteristics, personal motivation, teaching belief, education and career experience, and thinking style were used to assess on how teachers perceived creative teaching. Using the teachers' background information, the current study investigated teachers' creative teaching perceptions.
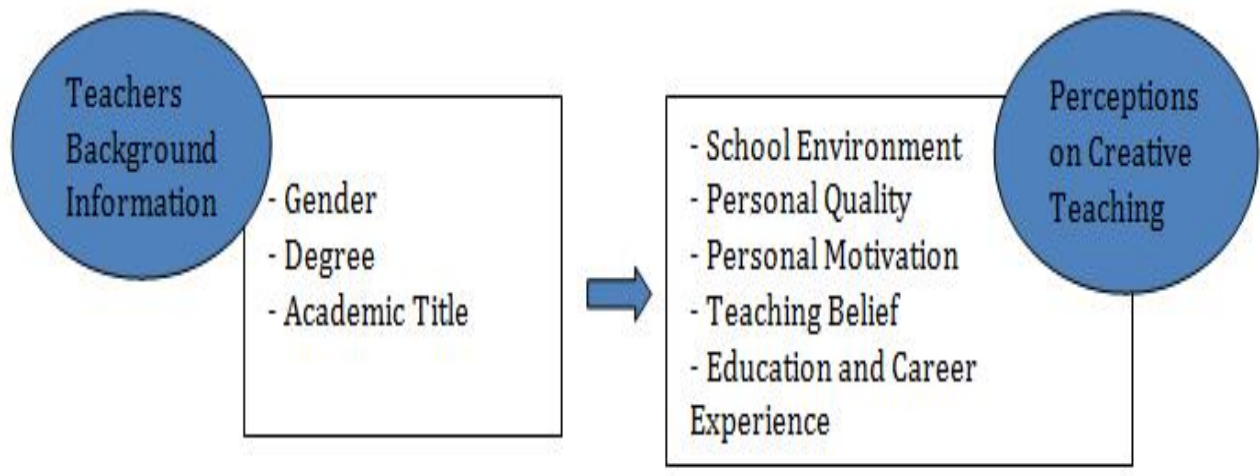

FIGURE 1. Research framework on creative teaching perceptions

\section{Research Hypotheses}

1. Teachers with different genders hold different views on creative teaching. 2. Teachers with an academic title have different perceptions from the ones without an academic title. 3. Teachers having different degrees perceive differently on creative teaching.

\section{METHOD}

This study is intended to find out the perceptions of language teachers in private universities on creative teaching based on their background information. Data were collected from 164 English language teachers in five different private universities in Thailand in academic year of 2015. These included Bangkok University, Hua Chiew Chalemprakiet University, Rangsit University, Saint John University, and Sripatum University. All these universities put emphasis on creative teaching in their mission. The demographic information of the 
respondents in terms of gender, age, degree, academic title, and years of teaching experience were investigated, and it was found that $68.3 \%$ of the surveyed respondents were all female while $31.7 \%$ were male. $30.5 \%$ of them were between ages $41-50$. For educational level, most of them (71.9\%) held a Master's degree while $17.7 \%$ of them held Bachelor's degree, and $10.4 \%$ of them had Doctoral degree. $84.7 \%$ of them were not holding any academic title.

The respondents had different teaching experiences. 32.3\% of them had 21 years and above of teaching experience, $19.5 \%$ had 5 years and below; 11-15 years of teaching experience; $15.9 \%$ had $6-10$ years, while $12.8 \%$ of them had $16-20$ years of teaching experience.

TABLE 1. Mean scores of two summative tests and the number of students who passed each test

\begin{tabular}{lll}
\hline \hline Demographic Characteristics & Number & Percentage \\
\hline Gender & 52 & 31.7 \\
Male & 112 & 68.3 \\
Female & & \\
Age & 29 & 17.7 \\
$21-30$ & 42 & 25.6 \\
$31-40$ & 50 & 30.5 \\
$41-50$ & 33 & 20.1 \\
$51-60$ & 10 & 6.1 \\
61-70 & & \\
\hline Degree & 17 & 10.4 \\
Doctorate Degree & 11871.9 & \\
Master's Degree & 29 & 17.7 \\
Bachelor's Degree & & \\
\hline Academic Title & 25 & 15.2 \\
Holding & 84.7 & \\
Not Holding 139 & & \\
\hline Years of Teaching Experience & 32 & 19.5 \\
5 years and below & 26 & 15.9 \\
6-10 & 32 & 19.5 \\
11-15 & 21 & 12.8 \\
16-20 & 53 & 32.3 \\
21 years and above & & \\
\hline \hline
\end{tabular}

The study employed a questionnaire comprising two parts. The first part was about the respondents' background information inquiring about their age, gender, degree, academic title, and years of teaching experience. The second part looked into the teachers' perceptions on creative teaching and asked them to indicate how much they think each item is important for them or an institution to become effective in creative teaching. This part was adapted from the components of creativity proposed by Ammabile and Urban (1995) which can be summed up into cognitive, personality, motivation and environmental. Furthermore, the questionnaire adapted the factors influential in creative teaching mentioned in the study conducted by Hong, et al. (2012), Horng, et al. (2005), and Palanaippan (2009).

After examining those factors together, the factors generated from their studies were 
the school environment, personal quality/traits, and motivation, teaching belief, education and work experience, and thinking style. The draft of the questionnaire was examined by five specialists, two were doctorate graduates, and three of them had Master's degree and had their academic title. After the thorough revision of all the items, the questionnaire was piloted with 30 English language teachers from a private university during the second semester of academic year 2014. The pilot study showed a high reliability index of .92. This means that all the 30 items listed in the questionnaire were valid and reliable. After that the questionnaire was distributed to 164 language teachers from five universities, and data were statistically analyzed by SPSS/Window program, using Means, Standard Deviations, Independent-samples t-tests and One-way Analysis of Variance (ANOVA). Mean ranges used in this study were as follows: $1.00-1.50=$ very low, $1.51-2.50=$ low, $2.51-$ $3.50=$ moderate, $3.51-4.50=$ high, $4.51-5.00=$ very high .

\section{RESULTS}

Table 2 shows how much teachers thought the items in six categories namely, school environment, personal quality, personal motivation, teaching belief, education and career experience, and thinking style are important for them to become effective. As it can be seen from the result, the overall perceptions were important at a high level $(\bar{x}=4.01)$. When considering six categories, the order of importance can be arranged as follows: personal quality $(\bar{x}=4.21)$, thinking style $(\bar{x}=4.02)$, school environment $(\bar{x}=3.98)$, personal motivation ( $\bar{x}=3.81)$, teaching belief $(\bar{x}=3.77)$ and education and career experience $(\bar{x}=3.77)$. All of the categories were at a high level.

TABLE 2. Mean and standard deviation of teachers' perceptions shown in six categories

\begin{tabular}{lllll}
\hline \hline Categories of Creative Teaching & Mean & S.D. & Level of Perceptions & Rank \\
\hline School Environment & 3.98 & .78 & high & 3 \\
\hline Personal Quality & 4.21 & .66 & high & 1 \\
\hline Personal Motivation & 3.81 & .77 & high & 4 \\
\hline Teaching Belief & 3.77 & .68 & high & 5 \\
\hline Education and Career Experience & 3.77 & .68 & high & 5 \\
\hline Thinking Style & 4.02 & .65 & high & 2 \\
\hline Total & $\mathbf{4 . 0 1}$ & $\mathbf{. 5 9}$ & high & \\
\hline \hline
\end{tabular}

Hypothesis 1: predicted that teachers with different genders held different views on creative teaching.

The t-test was employed to examine their perceptions regarding the gender. The finding shows that male and female perceived creative teaching in terms of the six categories differently. Male teachers have higher perceptions than female in three categories: personal motivation ( $\bar{x}=3.87 / 3.78)$, personal quality $(\bar{x}=4.26 / 4.19)$, and teaching belief $(\bar{x}=$ 4.33/4.14). Female teachers, however, perceived higher perceptions than male in three categories. These categories included school environment $(\bar{x}=4.03 / 3.88)$, education and career experience $(\bar{x}=3.83 / 3.63)$, and thinking style $(\bar{x}=4.07 / 3.91)$. It was also found that female gender had a higher perception on creative teaching $(\bar{x}=4.02)$ than their male counterparts $(\bar{x}=3.98)$. However, the data did not reveal a significant difference between the two genders' perceptions ( $p>$.05). So, Hypothesis 1 stating that teachers with different genders held different views on creative teaching was rejected. 
TABLE 3. Comparisons of teachers' perceptions on creative teaching based on gender

\begin{tabular}{lllll}
\hline \hline Categories of Creative Teaching & Gender & $\mathbf{n}$ & $\mathbf{x}$ & $\mathbf{t}$ \\
\hline \multirow{3}{*}{ School Environment } & male & 52 & 3.88 & -1.14 \\
& female & 112 & 4.03 & \\
\hline \multirow{3}{*}{ Personal Quality } & male & 52 & 4.26 & .63 \\
& female & 112 & 4.19 & \\
\hline \multirow{3}{*}{ Personal Motivation } & male & 52 & 3.87 & .75 \\
& female & 112 & 3.78 & \\
Education and Career Experience & male & 52 & 4.33 & 1.92 \\
& female & 112 & 4.14 & \\
Thinking Style & male & 52 & 3.63 & -1.76 \\
\hline \multirow{2}{*}{ Total } & male & 52 & 3.83 & \\
\hline \hline
\end{tabular}

$* \mathrm{P}<.05$

Hypothesis 2: predicted that teachers with an academic title had different perceptions from the ones without an academic title.

When considering each category, it was found that teachers with academic title had higher perceptions on creative teaching than the ones without academic title in all categories. For teachers with academic title, they placed the most importance on the category of teaching belief $(\overline{\mathrm{x}}=4.40)$, followed by personal motivation $(\overline{\mathrm{x}}=4.14)$ and thinking style $(\bar{x}=4.26)$. For teachers without academic title, they placed the most importance on the category of personal quality ( $\bar{x}=4.18)$, followed by teaching belief $(\bar{x}=4.17)$, and thinking style $(\bar{x}=3.98)$. When t-test analysis was conducted to see whether any significant difference existed, the result reveals that teachers with an academic title had significantly

TABLE 4. Comparisons of teachers' perceptions on creative teaching based on academic title

\begin{tabular}{lllll}
\hline \hline Categories of Creative Teaching & Academic Title & $\mathbf{n}$ & $\mathbf{x}$ & $\mathbf{t}$ \\
\hline School Environment & holding & 25 & 4.17 & 1.31 \\
& not holding & 139 & 3.95 & \\
\hline Personal Quality & holding & 25 & 4.38 & 1.37 \\
& not holding & 139 & 4.18 & \\
\hline Personal Motivation & holding & 25 & 4.14 & $2.42^{*}$ \\
& not holding & 139 & 3.75 & \\
\hline Teaching Belief & holding & 25 & 4.40 & 1.84 \\
& not holding & 139 & 4.17 & \\
\hline Education and Career Experience & holding & 25 & 4.02 & 2.01 \\
& hot holding & 139 & 3.72 & \\
\hline Thinking Style & holding & 254.26 & $2.07^{*}$ & \\
& not holding & 139 & 3.98 & \\
\hline Total holding & $\mathbf{2 5}$ & $\mathbf{4 . 2 3}$ & $\mathbf{2 . 0 7}$ & \\
& not holding & $\mathbf{1 3 9}$ & $\mathbf{3 . 9 7}$ & \\
\hline \hline
\end{tabular}

$* \mathrm{P}<.05$ 
different perceptions on creative teaching than the ones without an academic title only in two categories: personal motivation and thinking style and in the overall mean score of perceptions at a significance level of .05. So, Hypothesis 2 stating that academic title had an effect on perceptions was accepted.

Hypothesis 3: predicted that teachers with different academic degrees perceived creative teaching differently.

The result shows that teachers with doctoral degree had higher perceptions than the others in four categories comprising school environment, personal quality, education \& career experience and thinking style while teachers with Bachelor's degree had higher perceptions than the others in two categories comprising personal motivation and teaching belief. When an ANOVA test was used to analyze the data, it was found that there were statistically significant differences in all categories and in the overall perceptions based on their academic degree. As a result, the hypothesis stating that academic degree had an impact on perceptions was rejected. This means that teachers with different academic degrees did not differ in their perceptions about creative teaching.

TABLE 5. Comparisons of teachers' perceptions on creative teaching based on academic degree

\begin{tabular}{|c|c|c|c|c|}
\hline 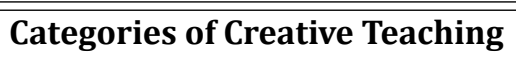 & Academic Title & $\overline{\mathrm{nn}}$ & $\overline{\overline{\mathbf{x}}}$ & 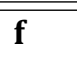 \\
\hline \multirow[t]{3}{*}{ School Environment } & Doctoral & 17 & 4.18 & .60 \\
\hline & Master & 118 & 3.96 & \\
\hline & Bachelor & 29 & 3.95 & \\
\hline \multirow[t]{4}{*}{ Personal Quality } & Doctoral & 17 & 4.36 & .57 \\
\hline & Master & 118 & 4.18 & \\
\hline & Bachelor & 29 & 4.23 & \\
\hline & Doctoral & 17 & 3.79 & .51 \\
\hline \multirow[t]{3}{*}{ Personal Motivation } & Master & 118 & 3.78 & \\
\hline & Bachelor & 29 & 3.94 & \\
\hline & Doctoral & 17 & 4.13 & 1.51 \\
\hline \multirow[t]{2}{*}{ Teaching Belief } & Master & 118 & 4.17 & \\
\hline & Bachelor & 29 & 4.37 & \\
\hline \multirow{3}{*}{ Education and Career Experience } & Doctoral & 17 & 3.86 & \\
\hline & Master & 118 & 3.79 & .82 \\
\hline & Bachelor & 29 & 3.63 & \\
\hline \multirow{3}{*}{ Thinking Style } & Doctoral & 17 & 4.09 & \\
\hline & Master & 118 & 4.03 .45 & \\
\hline & Bachelor & 29 & 3.92 & \\
\hline \multirow{3}{*}{ Total } & Doctoral & 17 & 4.07 & \\
\hline & Master & 118 & 3.99 & .11 \\
\hline & Bachelor & 29 & 4.01 & \\
\hline
\end{tabular}

$* \mathrm{P}<.05$

\section{DISCUSSION AND CONCLUSION}

The first discussion is on the finding which revealed six categories namely, school environment, personal quality, personal motivation, teaching belief, education and career experience, and thinking style to be at a high level. This means teachers placed a lot of importance on all categories. In addition, the category of personal quality was considered the most important category in creative teaching. This is probably because qualified teachers can make more effective teaching. In this regard, teachers need to be involved in making 
learning more interesting and using innovative approaches in the classroom (Horng, et al., 2005). The finding was found to be in accordance with Hong, et al. (2012) who emphasized the teacher quality in that teachers should be able to utilize their own creativity to design systematic teaching solutions, adopt appropriate teaching techniques, and change teaching methods or arrange reasonable and effective teaching activities while teaching.

The next interesting issue to be discussed is teachers' background information. Based on the finding, it's interesting to see that one factor having an impact on teachers' perceptions at a significance level of .05 was academic title. Teachers with an academic title had higher perceptions of creative teaching than those without an academic title. This is probably because the ones with an academic title require more updated information and knowledge to produce written work and research. The issue of cultivating students' creativity is very interesting to them as their teaching practice has to be transformed accordingly. As such, teachers with academic title are the group that the university can depend on the most to gain new ideas of how creative learning environments can be made. In this regard, the university may have a meeting that allows those teachers to discuss and share what they have learned.

Regarding the factor of gender, female gender had a higher perception on creative teaching $(\bar{x}=4.02)$ than their male counterpart $(\bar{x}=3.98)$. However, the mean scores were not significantly different. This may be because all teachers realize the mission of the university. That is, the development of students' creativity has been an important task. They know that they have to go to the same direction. In addition, creative teaching has been incorporated in the Thai curriculum for quite some time. For instance, in language instruction, there were a lot of changes in the course activities at our university to support more creative teaching.

The last issue to be discussed is the factor of academic degree that teachers are holding (doctoral, master, bachelor). According to the findings, teachers with doctoral degree had higher perceptions than the other two groups in four categories comprising school environment, personal quality, education and career experience and thinking style. This indicated that higher education enabled them to see the importance of creative teaching. However, their perceptions were not much different. So, when the mean scores were compared, it was found that teachers did not differ in their perceptions of creative teaching at a significant level. This is probably because the policy about creativity and creative teaching is a direction where teachers are heading to. All teachers have been always informed of the necessity to accept any changes that may occur both in the process of teaching and working.

\section{LIMITATIONS AND RECOMMENDATIONS}

This study has some limitations and room for improvement. In this study researcher employed a survey design for collecting data, however, it is believed that such data could generate common method bias or social desirability bias. Hence, future researches must replicate this study with mixed method design and generate results.

\section{REFERENCES}

Amabile, Teresa M. 1989. Growing up creative. New York, NY: Crown.

Blagg, Nigel. 1999. Can we teach intelligence. Hillsdale, NJ: Lawrence Erlbaum Associates.

Cropley, Arthur J. 1992. More ways than one: Fostering creativity. Norwood, NJ: Ablex Publishing Corporation.

Cropley, Arthur J. 2009. Creativity in education and learning-A guide for teachers and educators. Westport, CT: Ablex Publishing.

Fryer, M. 1996. Creative teaching and learning. London, UK: Paul Chapman. 
Hong, Jon-Chao, Jeou-Shyan Horng, Lih-Juan Lin, Shih-Hui Chang, Hui-Chuan Chu, and Chan-Li Lin. 2012. The questionnaire construction of creative teaching factors. URL: goo.gl/93znXN (accessed August 7, 2016).

Mayer, Richard E. 1989. Cognitive views of creativity. Creative teaching for creative learning. Contemporary Educational Psychology 14, no. 3: 203-211. DOI: 10.1016/0361-476X(89)90010-6.

Morris, Wayne. 2006. Creativity its place in education. URL: goo.gl/zZ75f3 (accessed August 11, 2016).

Newton, DP, and Newton LD. 2009. Some students and teachers'conceptions of creativity in school science. Research in Science \& Technological Education 27, no. 1: 45-60. DOI: $10.1080 / 02635140802658842$

Osborn, Alex. 1993. Applied imagination. 3rd ed. Buffalo, NY: Creative Education Foundation.

Palaniappan, Ananda K. 2009. Creative teaching and its assessment. Paper presented the 12th UNESCO-APEID International Conference on Quality Innovations for Teaching and Learning, Bangkok, Thailand, 24-26 March.

Rhodes, Mel. 1961. An analysis of creativity. Phi Delta Kapan 42, no. 7: 305-310.

Romo, Manuela., and Vicente Alfonso. 2003. Implicit theories of Spanish painters. Creativity Research Journal 15, no. 4: 409-415. DOI: 10.1207/S15326934CRJ1504_8

Rosenthal, Robert. 1991. Teacher expectancy effects: A brief update 25 years after the Pygmalion experiment. Journal of Research in Education 1, no. 1: 3-12.

Runco, Mark A. 2004. Creativity. Annual Review of Psychology 55, no. 1: 657-687. D0I: 10.1146/annurev.psych.55.090902.141502

Runco, Mark A., and Diane J. Johnson. 2002. Parent's and teacher's implicit theories of children's creativity: A cross-cultural perspective. Creativity Research Journal 14, no. 3/4: 427-438. DOI: 10.1207/S15326934CRJ1434_12

Slabbert, Johannes. 1994. Creativity and education revisited: Reflection in aid of progression. Journal of Creative Behaviour 28, no. 1: 60-69. DOI: 10.1002/j.2162-6057.1994.tb00720.x

Starko, Alane J. 2000. Creativity in the classroom: School in the curious delight. New Jersey, NJ: LEA.

Torrance, Paul E. 1962. Guiding creative talent. Englewood Cliffs, NJ: Prentice-Hall, Inc.

Torrance, Paul E., and Richard E. Mayer. 1976. LA enseñanza creativa. Madrid, Spain: Santillana.

Walberg, Herbert J. 1991. Creativity and talents as ways of creativity. In The nature of creativity at work: Contemporary psychological perspectives, ed. Robert J. Sternberg: 340- 362. Cambridge, NY: Cambridge University Press. 